Article

\title{
Effect of different salinities gradient on fatty acid composition, growth, survival and reproductive performance of Moina macrocopa (Straus 1820) (Crustacea, Cladocera)
}

\author{
Nadiah W. Rasdi ${ }^{1 *}$, Hidayu Suhaimi ${ }^{1}$, Atsushi Hagiwara ${ }^{2}$, Mhd Ikhwanuddin ${ }^{3}$, Mazlan A. G. ${ }^{3}$, Amirah \\ Yuslan ${ }^{1}$, Syarifah Syed Omar ${ }^{1}$ \\ 1 School of Fisheries and Aquaculture Sciences, Universiti Malaysia Terengganu, Kuala Nerus 21030, Kuala Terengganu 1; \\ nadiah.rasdi@umt.edu.my (N.W.R); hidayusuhaimi02@gmail.com (H.S.); amirahyuslan@gmail.com (A.Y.); \\ mag@umt.edu.my (M.A.G.); syarifahnajuwa94@gmail.com (S.N) \\ 2 Graduate School of Fisheries and Environmental Sciences, Bunkyo 1-14, Nagasaki 852-8521, Japan; hagiwara@ nagasaki- \\ u.ac.jp (A.H) \\ 3 Institute of Aquaculture Tropical, Universiti Malaysia Terengganu, Kuala Nerus 21030, Malaysia 3; \\ ikhwanuddin@umt.edu.my; (M.I) \\ * Correspondence: nadiah.rasdi@umt.edu.my ; Tel.: +6096685047
}

\begin{abstract}
Salinity is a known factor which shapes population dynamics and community structure through direct and indirect effects towards aquatic ecosystems. The responses of Moina macrocopa (Cladocera) collected from Setiu Wetland lagoon (Terengganu) were evaluated through manipulative laboratory experiments to understand the ability of M. macrocopa to tolerate under high salinity stress. Specifically, the fatty acid composition, growth, survival and reproduction of this cladocerans species were examined. Sodium chloride $(\mathrm{NaCl})$ were used in the treatments water with the concentration $0,4,6,8,12$, and 15psu. Fatty acid levels were determined using Gas Chromatography and Mass Spectrophotometry (GC-MS). Results clearly indicate that normal conditions give the highest content of fatty acid, especially the polyunsaturated fatty acid content like EPA (eicosapentaenoic acid), ALA (alpha-linoleic acid), ARA (arachidonic acid) and DHA (docosahexaenoic acid). Furthermore, M. macrocopa survival also was best at $0 \mathrm{psu}$, with percentage reached $98 \%$, whereas the opposite occurred at $15 \mathrm{psu}$, with approximately $9 \%$ of viable animals survived. On other aspects, M. macrocopa also showed the highest reproduction rate at 0 psu (e.g. average initial age of reproduction, $4.33 \pm 0.58$ days) compared with other salinities level. Interestingly, the difference in terms of growth at different salinities was unapparent, an unexpected outcome when adverse effects such as osmoregulation pressure on the organism are considered. Based on the results, we conclude that M. macrocopa can only tolerate salinity below 8psu and, is unable to withstand stressful environmental condition engendered with salinities above 8psu.
\end{abstract}

Keywords: freshwater zooplankton; Moina; salinity tolerance; $\mathrm{NaCl}$; fatty acid

\section{Introduction}

Industrialization and urbanization often cause a variety of negative impacts on the aquatic ecosystem, especially the freshwater ones (e.g., due to proximity to source and, lower volumes and exchange rates or dilution). Salt concentrations of freshwater habitat have increased because of industrial activities and urbanization, with resultant impacts on freshwater animals (Ghazy et al., 2009). Agricultural activities, urbanization and other coastal development projects are rapidly taking place in Southeast Asia that can drastically change the geomorphological structures (M. N. Lani et al., 2018). Setiu Wetland lagoon is considered as a major 
location for brackish water mariculture activity including finfish cage, pond culture and shellfish farming (M. N. Lani et al., 2018). This anthropogenic interference has both directly and indirectly degraded the natural environment of Setiu Wetland lagoon. Major concerns regarding anthropogenic activities at Setiu Wetlands include resulting water contamination, coastal destruction and, productivity impact (Zaleha et al., 2018). The increase of water sea levels and, coastal erosions have contributed tremendously to salinity changes (Ekaterina et al., 2017) and, have damaged aquatic habitat and ecosystems (Reliana, 2012). Aquatic organisms are sensitive towards changes in water condition. Small fishes are more opportunistic in nature that they can adapt and survive in stressful conditions found in shallow lagoons (Zaleha et al., 2018). Zooplankton is an important community in the aquatic ecosystem for energy transfer from the primary producer to fishes (Soni and Thomas, 2014). Factors such as species of zooplankton and ecosystem type heavily influence the feeding of small fishes (Souza et al., 2013). Ecosystem condition affects both foraging efficiency and predation risk and, may beneficially increase the former and decrease the latter in fish (Scharf, 2006).

Zooplankton species distribution and abundance are influenced by various environmental factors such as water transparency, climate change and food nutritional content. The abundance and diversity (El Gamal et al., 2014) of zooplankton and phytoplankton (Ekaterina et al., 2017) are affected by the increase of salinity in the environment. Therefore, water salinity shift also can alter the original taxa composition and ecological process, such as primary productivity, decomposition, nutrient cycles and, food web function (Emanuela et al., 2010). Salinity increase in freshwater has the potential to reduce zooplankton richness especially in the cladoceran community and thus, change adaptation of the species to a more salt tolerant species (Reliana, 2012). Research on cladocerans has been widely conducted, due to their ecological importance, sensitivity towards environmental changes and ease of handling (Sarma \& Nandini, 2006; Ana Carolina et al., 2011). Cladocerans are an important group in the zooplankton community with most of the species living in freshwater environments with salinities of $<1$ psu (Ghazy et al., 2009). This is due to osmoregulation adaptations that only allows them to tolerate lower salinity levels (Bruno et al., 2012). A few of cladoceran species have shown an ability to adapt to salinity changes. However, this adaptation can impact the growth and reproduction of cladoceran species in comparison with response to their original habitat. Cladocerans are reported to be abundant in freshwater ecosystems as compared to brackish water environments (Forro et al., 2008; Erondu et al., 2017). However, there are a few cladoceran species that can live in a saline environment; mostly from brackish water species which can tolerate salinity beyond 13psu such as Daphnia pulex, Daphnia thomsoni and Daphnia magna (Bruno et al., 2012).

Moina sp., commonly referred to as water fleas, are crustaceans within the family of Moinidae which inhibit freshwater and also thrives in both brackish and marine environment. The reproductive cycle of Moina sp. has both a sexual and asexual phase. Normally, the population consists of all females that reproduce asexually. Under optimum conditions, Moina sp. reproduce at only 4 to 7 days of age, with a brood size of 4 to 22 per female (Rottman et al., 2014). Broods are produced every 1.5 to 2.0 days (Rottman et al., 2014), with most females producing 2 to 6 broods during their lifetime (Rottman et al., 2014). Under adverse environmental conditions, males are produced, and sexual reproduction occurs resulting in resting egg (ephippia) production. This case is similar to brine shrimp eggs production. The stimuli for the switch from asexual to sexual reproduction in populations of Moina sp. is an abrupt reduction in the food supply and significant change in environmental conditions. The density of Moina sp. cultures routinely reaches densities of 5,000 individuals per Litre $(19,000 /$ gallon) and therefore, they are well adapted to intensive culture (Rottman et al., 2014). M. macrocopa are rich in protein and nutrients. They are excellent live foods for fish and prawn larvae when compared to other live feeds such as rotifer and Artemia (Loh, 2012). However, the fatty acid content of Moina sp. varies when they are cultivated with different culture media and different levels of environmental stress (Loh, 2012).

Studies have shown that lowering ambient temperature tends to increase the production of C20-22 polyunsaturated fatty acid production in planktonic crustacean (Zaleha et al., 2014). However, the study on the impact other environmental parameters on freshwater cladocerans, such as salinity change, is still limited and some quantitative data are only available on the fatty acid profiles of zooplankton at different temperatures but, salinity-induced effects on the fatty acid composition of M. macrocopa have not been evaluated (Gama-Flores et al., 2015). Lipids and fatty acids are structural components of cell membranes that play an important role in growth, survival and reproduction of aquatic organisms, especially in the early life stages of larvae (Gama-Flores 
et al., 2015). Salinity changes in the freshwater habitat can exert an impact on the distribution or, community structure of water fleas thus, affecting feeding behavior and indirectly, also having a slightly impact on nutritional composition. The current study investigated the tolerance of $M$. macrocopa in response to salinity changes. The objectives of this study were to evaluate the ability of $M$. macrocopa in adapting to a saline environment (Inger et al., 2010) and, to investigate the potential of M. macrocopa in saline tolerance (Bruno et al., 2012). Specifically, the study aimed to assess the impact of salinity on fatty acid composition, growth, survival and, reproduction of $M$. macrocopa when exposed to different salinity levels. M. macrocopa are also considered as a useful indicating animal to evaluate impacts of increasing salinity on the aquatic environment.

\section{Materials and Methods}

\subsection{Cultivation of Moina macrocopa}

Live M. macrocopa were collected from the lagoon of Setiu Wetland, located in the state of Terengganu (N $5^{\circ}$ $68^{\prime} \mathrm{E} 102^{\circ} 70^{\prime}$ ), and cultured in the Hatchery of University Malaysia Terengganu prior to use in experiments. Zooplankton net (sizes from 50 until $200 \mu \mathrm{m}$ ) was used to sample zooplankton in the sampling area. Salinity, dissolved oxygen and temperature of water at the sampling site was measured using a YSI Multi-probe instrument (YSI Model 33).

Moina sp. were cultured in a $100 \mathrm{~mL}$ flask filled with freshwater and, were periodically upscaled to $2000 \mathrm{~L}$ tanks for mass culture once the density reached 10individuals per milliliter (ind/mL). Water parameters were maintained at $26^{\circ} \mathrm{C}$ to $30^{\circ} \mathrm{C}$ with a photoperiod of $12 \mathrm{~h} \mathrm{light:} 12 \mathrm{~h}$ dark (Loh et al., 2012). In the current study, individuals in the neonates' stage $>24$ hours old, were used (Ghazy et al., 2009) and, isolation of neonates was carried out using nets with different mesh sizes (50 $\mu \mathrm{m}$ until $200 \mu \mathrm{m})$. During the experiment, M. macrocopa were fed with fresh food of microalgae at a concentration of $14 \times 107$ cells/mL (Gani et al., 2016). Microalgae Nannochloropsis sp. were used as feed to maintain similarity with the original habitat food resource. Pure microalgae stock was cultured at room temperature $(25 \mathrm{oC}$ until $28 \mathrm{oC})$ with 24 hours of light. The algal strain Nannochloropsis sp. was obtained from the UMT hatchery algal laboratory and, the algae were cultured as feed for M. macrocopa. Microalgae were harvested when the culture reached the exponential phase (Hasnun et al., 2011) or before the decline phase (Rihab et al., 2013). To maintain the salinity of M. macrocopa cultivation, the Nannochloropsis sp. was cultured at a lower salinity by gradually decreasing the salinity until it reached the same range of M. macrocopa cultivation.

Changes in growth, survival and reproduction of M. macrocopa were examined at six different salinities. The salinity level used was within the range of those able to occur within the original habitat of Setiu Lagoon. According to M. N. Lani et al., (2018) and Suratman et al., (2014), the water salinity in Setiu Wetland ranges from Opsu until 35.0psu. In the laboratory, M. macrocopa was tested at 0, 4, 6, 8, 12, and 15psu (El Gamal et al., 2014), for the similarity of the range of salinity in Setiu wetland. The effect of salinity treatments was conducted by using sodium chloride $(\mathrm{NaCl})$ solution as test waters. Every treatment ran in parallel with control in three replicates, each replicate contained 10 neonates in $100 \mathrm{~mL}$ test water in $250 \mathrm{~mL}$ glass beakers. The artificial test water was diluted with the synthetic freshwater media to the respective test salinity. Test media were prepared by diluting saline water with synthetic freshwater media until the required salinities were recorded with a salinity conductivity- temperature Meter (YSI Model 33). The culture medium (0psu) was used as a control to mimic the original habitat of freshwater M. macrocopa in nature with no salinity level.

The average percentage survival of M. macrocopa was determined every alternate day by using a zooplankton counting chamber. The initial density is known, the final density of $M$. macrocopa was then recorded to generate a survival estimate (final density divided by initial counted density). The growth of $M$. macrocopa was determined daily by measuring body length (from the base of the caudal spine to the anterior edge of the head) with a projection microscope. The experiment was carried out for 21 days until all the cohort dies. To measure the reproductive capacity of $M$. macrocopa, life table parameter was used to record and analyze reproduction data. Life table variables included the initial age at maturation, longevity (days), survival/survivorship, average 
longevity, gross reproduction rate, net reproduction rate, generation time and, life expectancy. These variables were estimated as follows:

Age of first maturation (day) $=$ age at which the first brood appears from a female

Longevity (day) $=$ the average number of days of survival of the female

Survival/Survivorship $=\sum l_{x}$

Average longevity $=\sum \frac{n_{x}}{n}$

Gross reproduction rate $=\sum m_{x}$

Net reproduction rate $\left(R_{0}\right)=\sum l_{x} m_{x}$

Generation time $(\mathrm{T})=\sum \frac{l_{x} m_{x} x}{R_{0}}$

Life expectancy $\left(e_{x)}=\frac{T_{x}}{n_{x}}\right.$

Where,

$l_{x}=$ Proportion individual surviving to age $\mathrm{x}$

$n_{x}=$ Number of individual alive for each age class

$\mathrm{n}=$ Number of animals

$m_{x}=$ Age-specific fecundity (number of neonates produced per surviving female at age $x$ )

$T_{x}=$ Generation time at age $\mathrm{x}$

The intrinsic rate of population increases $(r)$ was calculated at the end of the experiment, and all the data were recorded at 15 until 16 days which was equivalent to the average lifespan (cycle) of M. macrocopa.

\subsection{Analysis of Fatty acid}

The zooplankton samples from each treatment were collected and freeze-dried prior to fatty acid analysis. Fatty acids (FAs) were extracted from freeze-dried M. macrocopa samples using a technique of Püttman et al., (1993) for both qualitative and quantitative examination. The extracted FAs were transesterified into fatty acid methyl esters (FAME) using strong acid at $80^{\circ} \mathrm{C}$ to $85^{\circ} \mathrm{C}$ for about an hour. After this treatment, purified water and hexane were added and, the upper organic layer transferred to a vial (Ichihara and Fukubayashi, 2010). This step was performed several times to achieve complete extraction of FAME. Samples were then dried and dissolved again in $20 \mu \mathrm{l}$ hexane to get 50 times concentration which removes all solvent peaks (i.e., toluen). The concentrated samples were then injected into gas chromatography-mass spectrometry (GC-MS) to read the spectra using caprylic acid $(\mathrm{CH} 3(\mathrm{CH} 2) 6 \mathrm{COOH})$ as an internal standard.

\subsection{Data analysis}

The data in this study were expressed as Mean \pm SD and were analyzed using one-way analysis of variance (ANOVA) to test the interaction between different ranges of salinity. Wherever applicable, post hoc Tukey's and Duncan multiple comparison tests were used to determine the significant differences of means between treatments. The level of significant difference was set at $P<0.05$.

\section{Results}

\subsection{Survival and growth of M. macrocopa in different salinities}

The survival and growth of M. macrocopa at different salinity levels are shown in Table 1 and 2 below. The highest survival of $M$. macrocopa occurred at $0 \mathrm{psu}(98.00 \pm 4.47 \%)(P<0.05$, refer to Table 1$)$ while the least survival (approximately 9\%) occurred at the salinity of 15psu. The survival rate at $4 \mathrm{psu}(92.67 \pm 7.23 \%$ ) and $6 \mathrm{psu}$ $(83.33 \pm 12.69 \%)$ were lower than in the control at 0psu salinity $(P>0.05$, refer to Table 1$)$. The growth of $M$. 
macrocopa showed a positive relationship with the lowering of salinities at $0 \mathrm{psu}(1.35 \pm 0.28 \mathrm{~mm}), 4 \mathrm{psu}(1.32 \pm 0.25$ $\mathrm{mm})$, and $6 \mathrm{psu}(1.30 \pm 0.25 \mathrm{~mm})$ with growth not being significantly affected. When the salinity reached $8 \mathrm{psu}$ $(0.72 \pm 0.61 \mathrm{~mm}), 12 \mathrm{psu}(0.39 \pm 0.54 \mathrm{~mm})$ and $15 \mathrm{psu}(0.23 \pm 0.43 \mathrm{~mm})$, the growth of $M$. macrocopa became slower. There was no significant difference between salinity ranges on the growth of M. macrocopa.

\subsection{Age of first maturation and average longevity}

The life table parameters of M. macrocopa are shown in Table 3. Salinity significantly influenced the initial age of reproduction $(P<0.05$, refer to Figure 2$)$. Females began to reproduce after $4.33 \pm 0.58$ days at 0 psu, compared longer delay for $4 \mathrm{psu}(5.33 \pm 0.58$ days), $6 \mathrm{psu}(6.00 \pm 0.58$ days) and $8 \mathrm{psu}(12.54 \pm 0.58$ days). However, there was no difference in reproduction between salinity $0 \mathrm{psu}$ and $4 \mathrm{psu}(P>0.05$, refer to Figure 2$)$. The average longevity of M. macrocopa was negatively correlated with salinity $(P>0.05$, refer to Figure 3$)$, average longevity being reduced with increase in salinity. Female of $M$. macrocopa survived longer at 0psu (12.33 \pm 0.58 days), compared with survivals at $4 \mathrm{psu}(9.67 \pm 0.58$ days), $6 \mathrm{psu}(9.67 \pm 0.58$ days) and $8 \mathrm{psu}(3.35 \pm 0.62$ days). Therefore, there was no significant difference in longevity between $4 \mathrm{psu}$ and $6 \mathrm{psu}(P<0.05$, refer to Figure 3$)$. Apart from that, there was no life table data can be recorded at $12 \mathrm{psu}$ and $15 \mathrm{psu}$, since all the M. macrocopa dead before being able to reproduce.

\subsection{Net reproduction rate and gross reproduction rate}

A net reproduction rate is the average number of females in a population produced during the lifetime of a female. The net reproduction rates of $M$. macrocopa ranged with rates for $0 \mathrm{psu}$ ( $12.35 \pm 0.77 \mathrm{offspring} / \mathrm{female}), 4 \mathrm{psu}$ ( $9.45 \pm 0.77$ offspring/female), $6 \mathrm{psu}$ (4.92 \pm 1.91 offspring/female) and $8 \mathrm{psu}(2.34 \pm 0.77$ offspring/female) that revealed significant difference between salinity and reproduction rate $(P>0.05$, refer to Figure 4$)$. The increase of salinity showed a statistical difference in gross reproductions rates of $M$. macrocopa $(P<0.05$, refer to Figure 5). The highest gross reproduction rate is at $0 \mathrm{psu}$ (13.33 \pm 0.58 offspring/female) followed by $4 \mathrm{psu}(12.00 \pm 1.00 \mathrm{offspring} / \mathrm{female})$, $6 \mathrm{psu}(11.00 \pm 0 \mathrm{E}-7$ offspring/female) and $8 \mathrm{psu}(5.34 \pm 0.58$ offspring/female). The net reproduction rates and gross reproduction rate of $M$. macrocopa decreased with salinity increases. However, there was no significant difference between the 0psu as control and $4 \mathrm{psu}(P>0.05$, refer to Table 3$)$, for net reproduction or gross reproduction rate.

\subsection{Generation time and intrinsic rate of population increase}

The time from laying of eggs to when an individual reaches sexual maturity is termed as generation time. The generation time for M. macrocopa was shorter at $6 \mathrm{psu}(6.98 \pm 60.96$ days) and longer at $8 \mathrm{psu}(11.23 \pm 0.77$ days). There was no significant difference in generation time between all the treatments $(P>0.05$, refer to Figure 6$)$. Based on the results, salinity showed an inverse relationship with the intrinsic rate $(P<0.05$, refer to Figure 7$)$. The M. macrocopa showed a high intrinsic rate at $0 \mathrm{psu}(0.16 \pm 0.007)$ compared with the rate at $4 \mathrm{psu}(0.052 \pm 0.028)$, 6psu $(0.061 \pm 0.004)$ and 8 psu $(0.078 \pm 0.004)$.

\subsection{Fatty acid compositions of M. macrocopa}

Fatty acid compositions which trigger the growth and survival rate of fish and crustaceans' larvae when fed on M. macrocopa are bold and shown in Table 4 . The fatty acid contents were significantly affected by salinity levels that cohorts were exposed to $(P<0.05)$. The highest level of fatty acids content considering saturated, and polyunsaturated fatty acids in $M$. macrocopa was recorded for the salinity of 0 psu $(P<0.05)$. The highest level of fatty acid as the sum of saturated, monosaturated and polyunsaturated, as a percentage of total fatty acids, was recorded in the control treatment at the lowest salinity level $(98.95 \%$, salinity $0 \mathrm{psu}$, refer to Table 4$)$. The amount of EPA (C20:5) in M. macrocopa were higher at the lowest salinity levels 0psu (35.21 $\pm 0.67 \%)$ than at higher salinity levels $(P<0.05)$. The increase of salinity from 0psu $(17.96 \pm 0.39 \%)$ to $15 \mathrm{psu}(6.54 \pm 0.81 \%)$ significantly abated the C18:1 monosaturated fatty acids in M. macrocopa $(P<0.05$, refer to Table 4$)$. The content of polyunsaturated fatty 
acids (PUFA) was significantly higher for salinity level treatment of 0psu (98.95\%) than at higher salinity levels in $M$. macrocopa $(P<0.05)$. The highest polyunsaturated fatty acids were recorded for eicosapentaenoic acid (EPA) $(35.21 \pm 0.67 \%)$ at the salinity of $0 \mathrm{psu}(P<0.05)$. The highest linoleic acid $(\mathrm{C} 18: 2)$ content in $M$. macrocopa was found for the salinity levels of $0 \mathrm{psu}$ and $4 \mathrm{psu}(31.66 \pm 0.64 \%, 23.69 \pm 1.6 \%$, respectively, $P<0.05$, refer to Table 4$)$. The highest alpha-linoleic acid (ALA) content in M. macrocopa was also found at 0 psu and $4 \mathrm{psu}(16.45 \pm 3.7 \%, 13.08 \pm 0.04$ $\%$, respectively, $P<0.05$, refer to Table 4). The amount of C18:4 in M. macrocopa decreased from $14.64 \pm 2.5$ to $4.68 \pm 0.01 \%$ as salinity levels increased from 0 psu to $15 \mathrm{psu}$, respectively $(P<0.05$, refer to Table 4$)$. Arachidonic acid (ARA) and Docosahexaenoic acid (DHA) are deficient, almost at non-detected (ND) levels, in M. macrocopa. DHA was the lowest FA analytical results among all the fatty acids found in $M$. macrocopa $(P<0.05$, refer to Table 4).

\subsection{Figures, Tables}

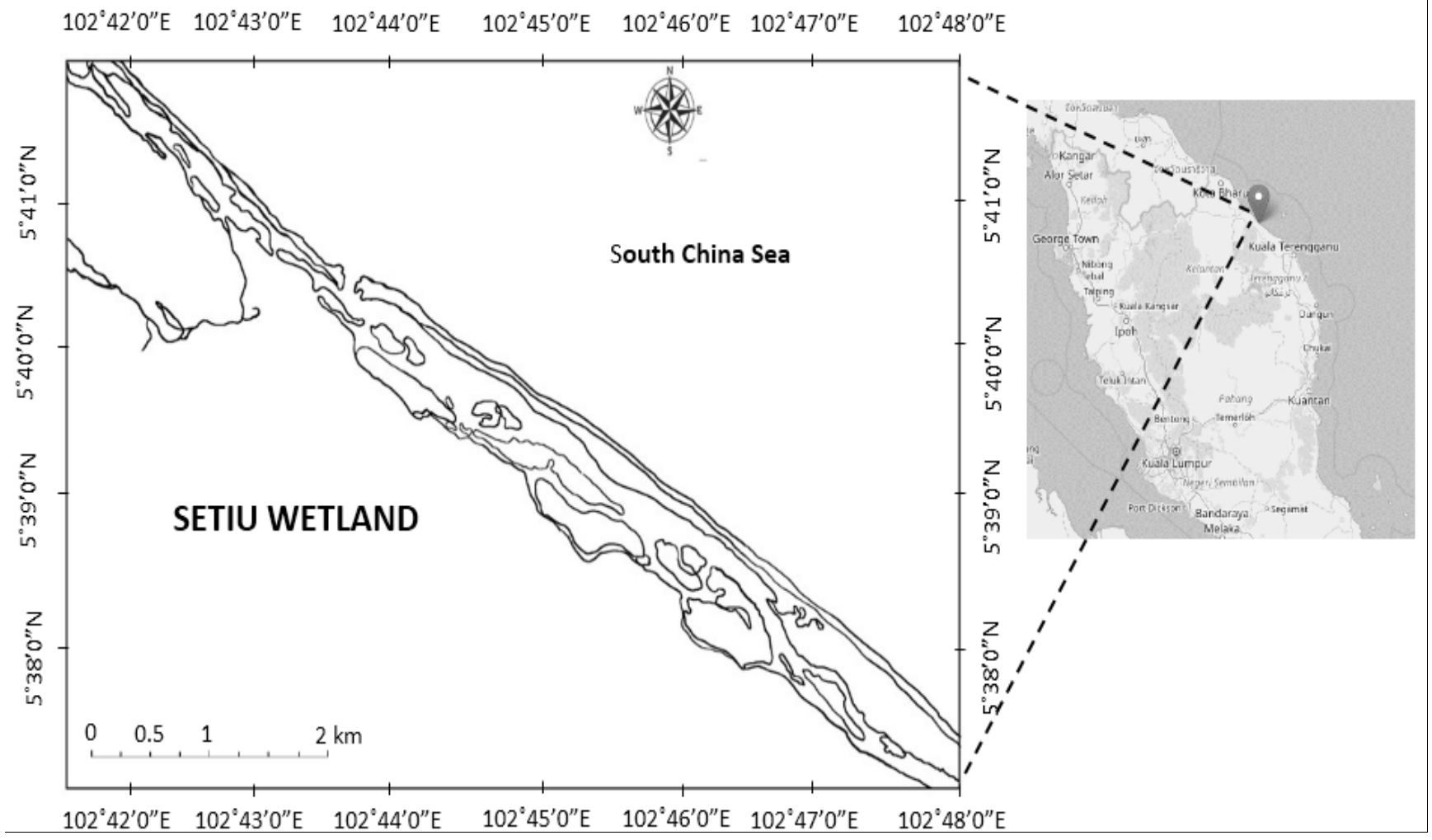

Figure 1. The location of sampling area at Setiu Wetland, Terengganu. 


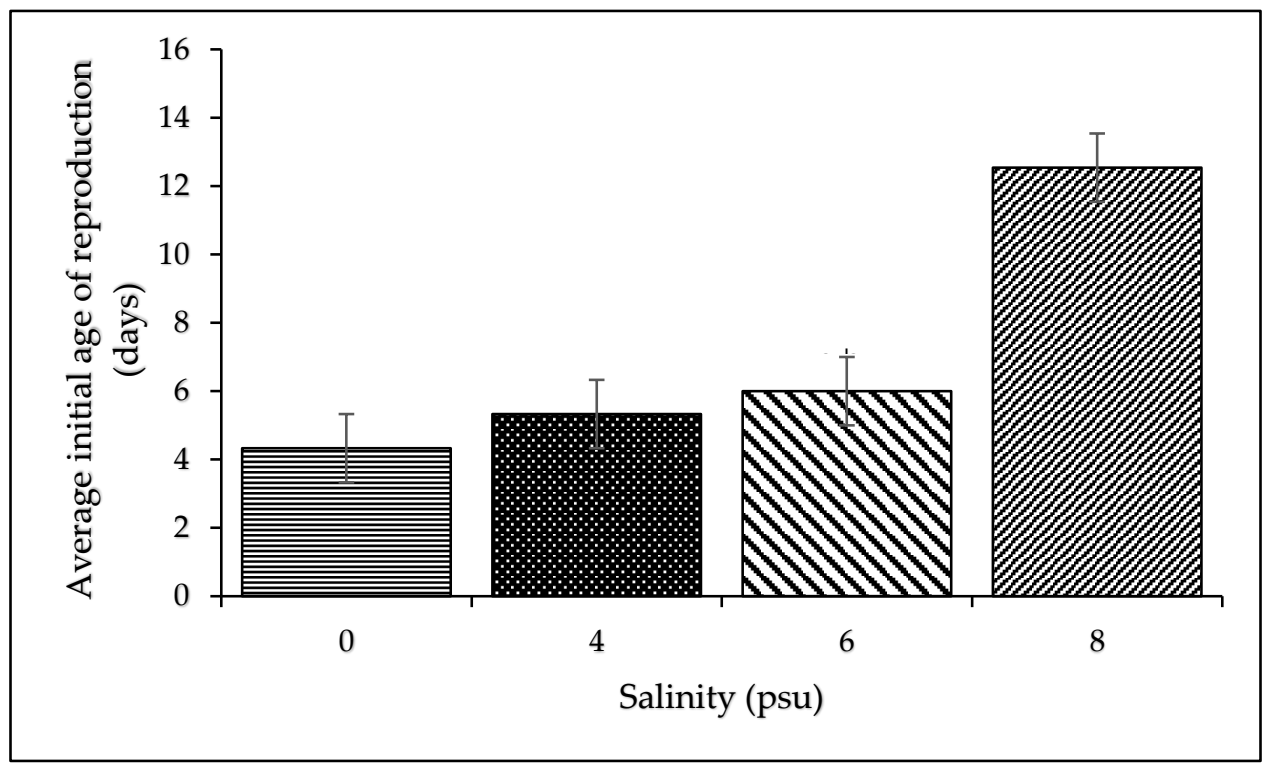

Figure 2. The average initial age of reproduction of $M$. macrocopa on different range of salinity. The different small letters indicate significant different between different salinity $(P<0.05)$.

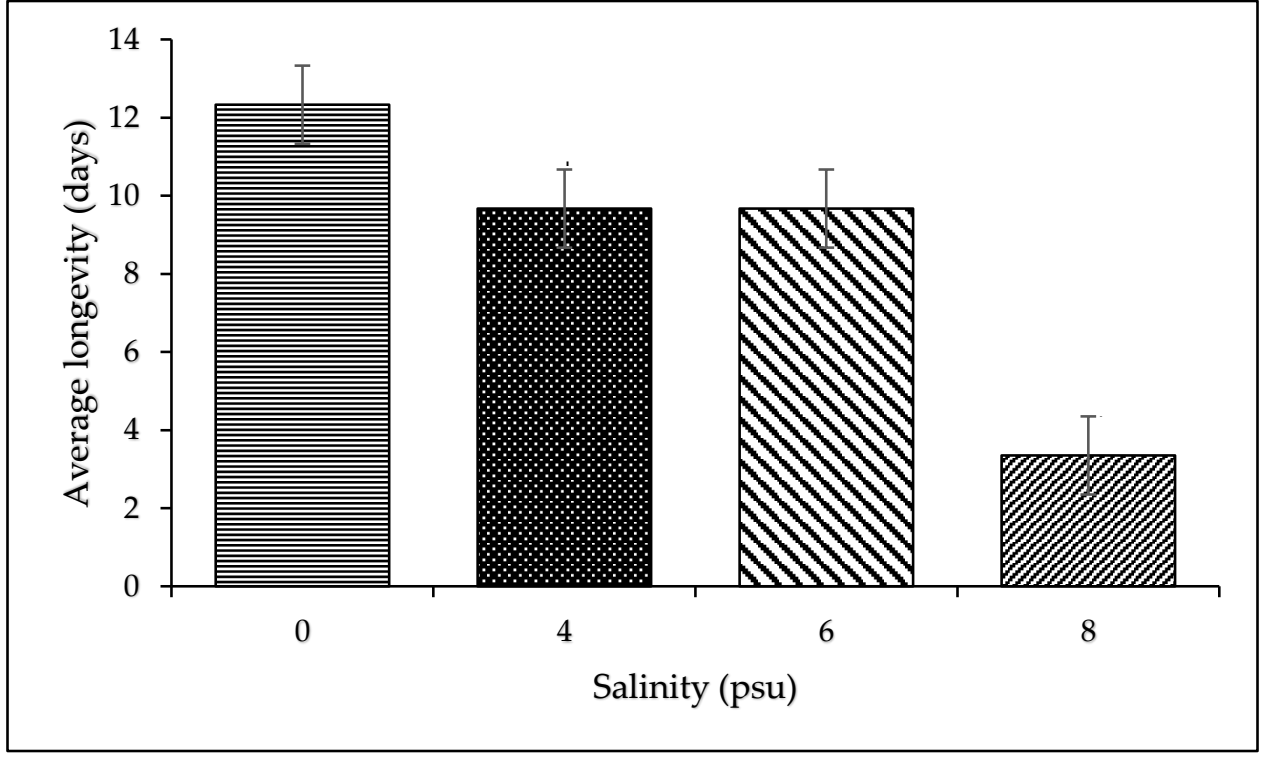

Figure 3. The average longevity of $M$. macrocopa on different range of salinity. The different small letters indicate significant different between different salinity $(P<0.05)$. 


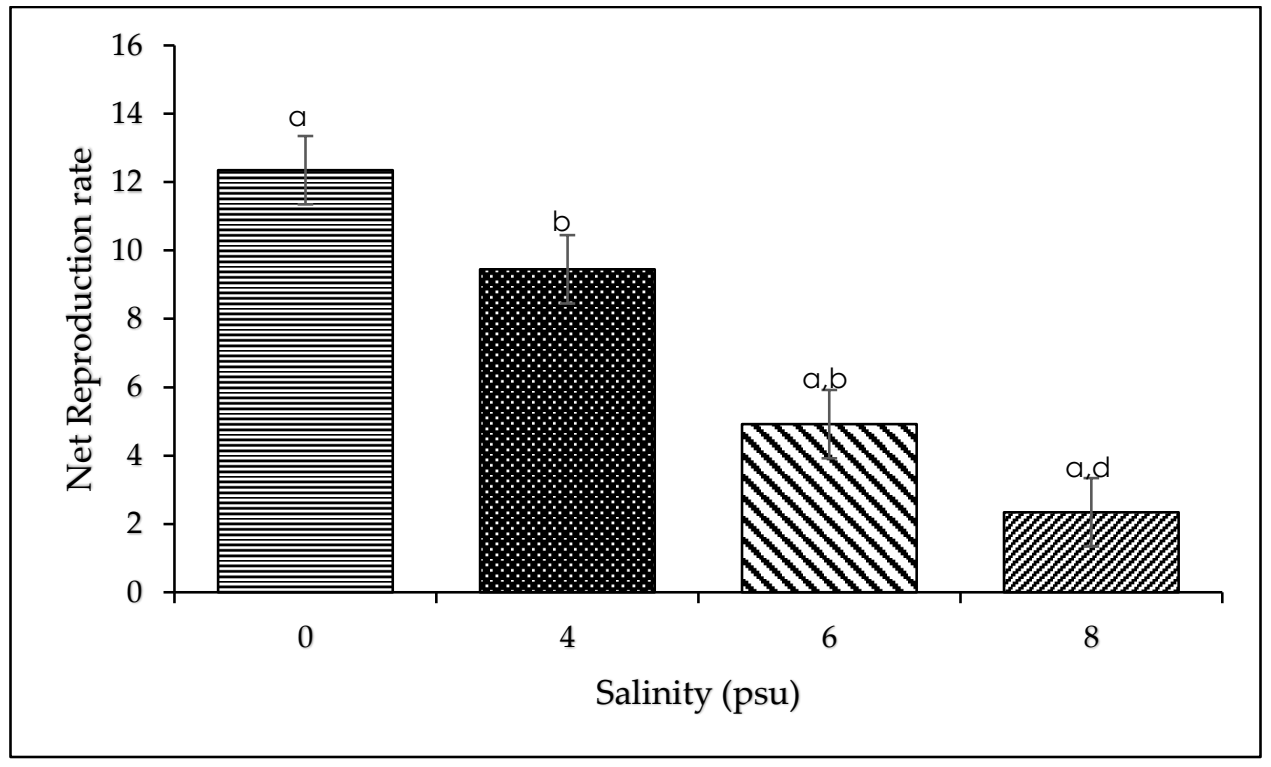

Figure 4. The net reproduction rate of $M$. macrocopa on different range of salinity. The different small letters indicate significant different between different salinity $(P<0.05)$.

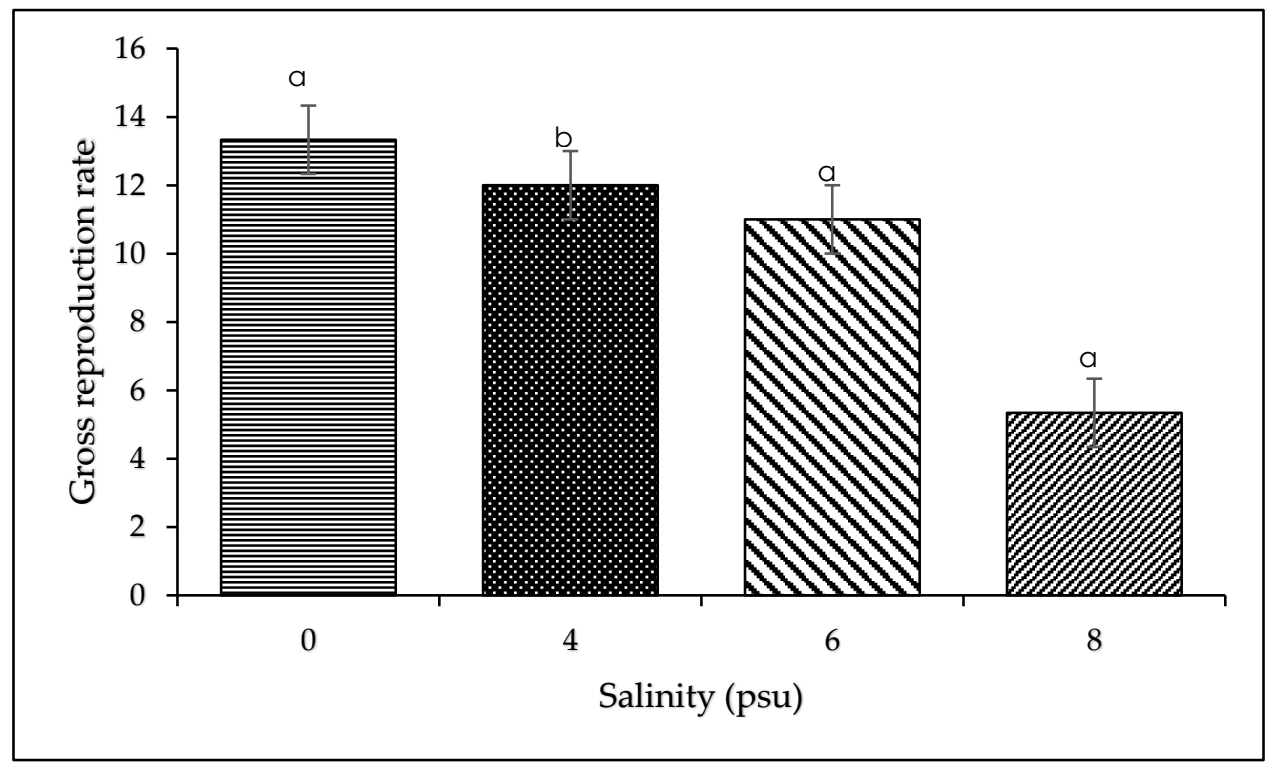

Figure 5. The gross reproduction rate of $M$. macrocopa on different range of salinity. The different small letters indicate significant different between different salinity $(P<0.05)$. 


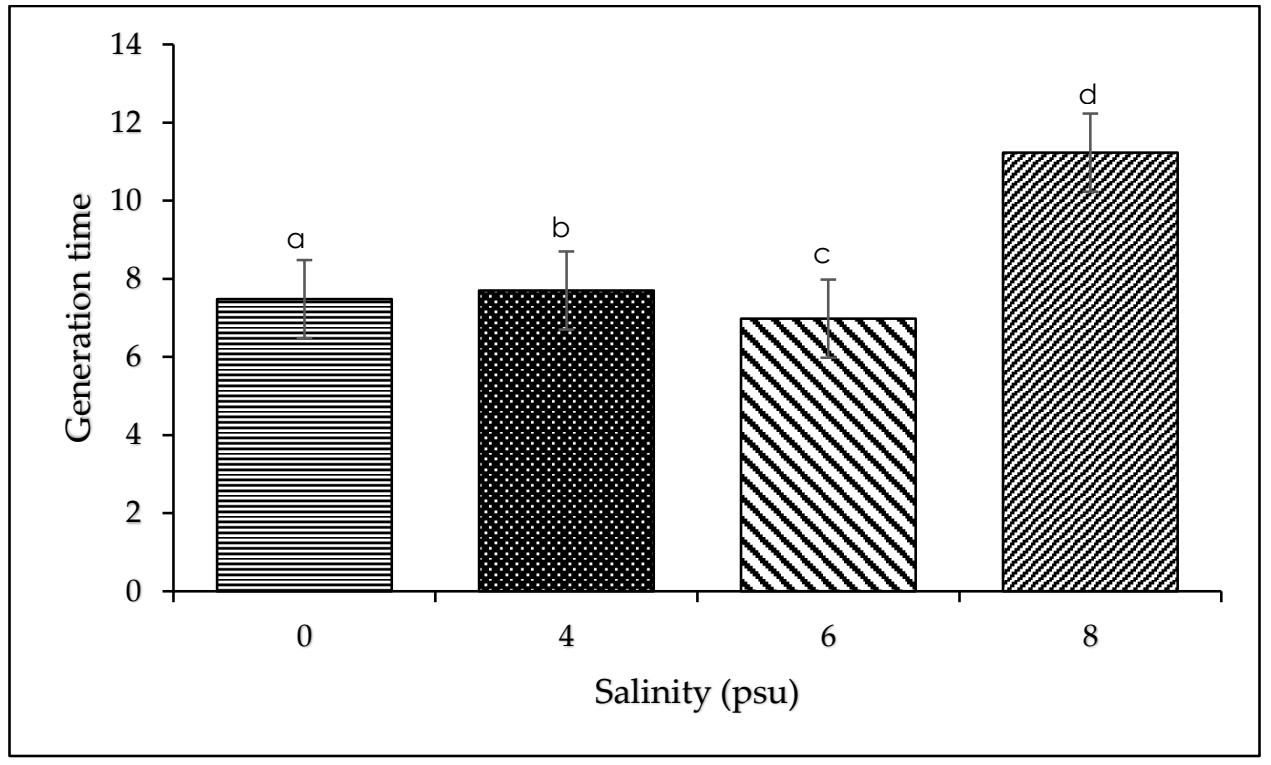

Figure 6. The generation time of $M$. macrocopa on different range of salinity. The different small letters indicate significant different between different salinity $(P<0.05)$.

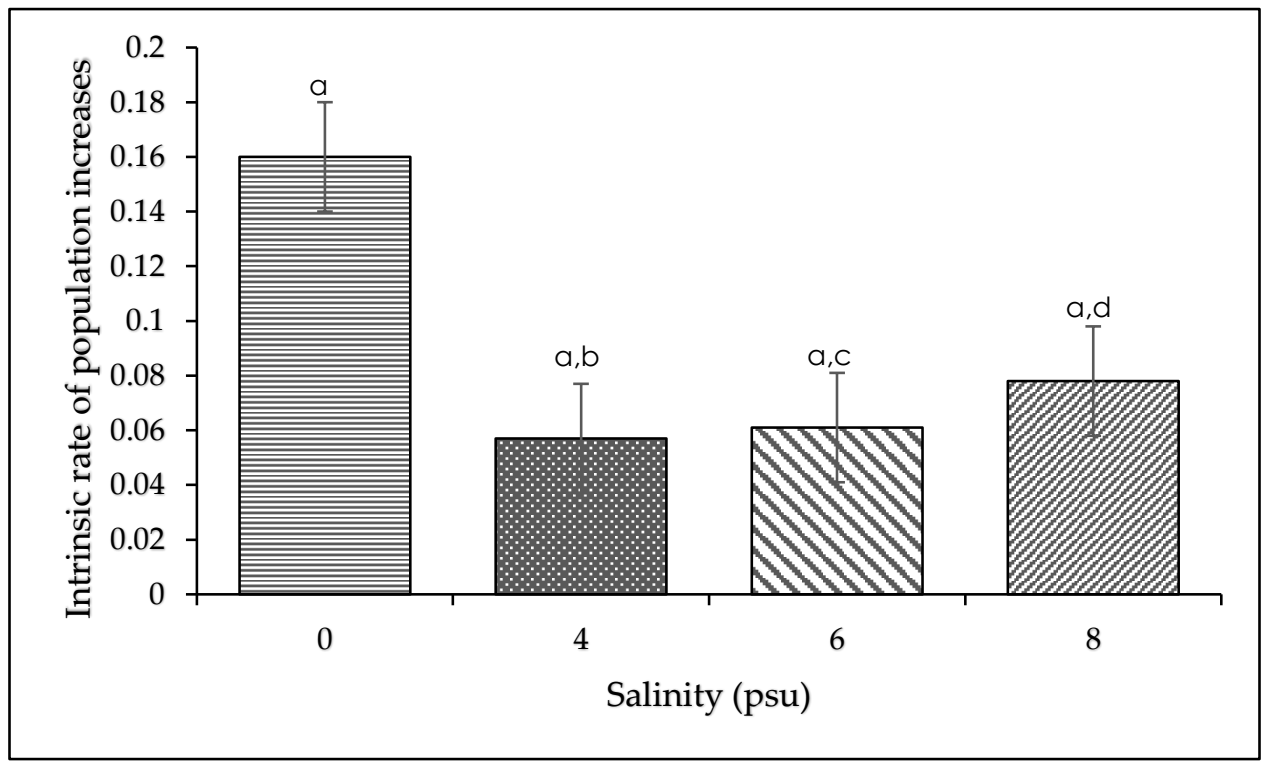

Figure 7. The intrinsic rate of population increase of $M$. macrocopa on different range of salinity. The different small letters indicate significant different between different salinity $(P<0.05)$. 
Table 1. The survival rate of M. macrocopa on different ranges of salinity. All values are mean \pm standard deviation $(\mathrm{n}=3)$. The different small letters indicate significant different between different salinity $(P<0.05)$.

\begin{tabular}{cc}
\hline Salinity (psu) & Survival rate (\%) (mean \pm SD) \\
\hline $\mathbf{0}$ & $98.00 \pm 4.47^{\mathrm{a}}$ \\
$\mathbf{4}$ & $92.67 \pm 7.23^{\mathrm{b}}$ \\
$\mathbf{6}$ & $83.33 \pm 12.69^{\mathrm{b}, \mathrm{c}}$ \\
$\mathbf{8}$ & $29.38 \pm 36.42^{\mathrm{d}}$ \\
$\mathbf{1 2}$ & $16.67 \pm 28.88^{\mathrm{d}, \mathrm{e}}$ \\
$\mathbf{1 5}$ & $8.96 \pm 25.44^{\mathrm{d}, \mathrm{f}}$ \\
\hline
\end{tabular}

Table 2. Growth rate of M. macrocopa on different ranges of salinity. All values are mean \pm standard deviation $(\mathrm{n}=3)$. The different small letters indicate significant different between different salinity $(P<0.05)$.

\begin{tabular}{cc}
\hline Salinity (ppt) & Growth rate $(\mathbf{m m})(\mathbf{m e a n} \pm$ SD) \\
\hline $\mathbf{0}$ & $1.35 \pm 0.28^{\mathrm{a}}$ \\
$\mathbf{4}$ & $1.32 \pm 0.25^{\mathrm{a}, \mathrm{b}}$ \\
$\mathbf{6}$ & $1.30 \pm 0.25^{\mathrm{a}, \mathrm{c}}$ \\
$\mathbf{8}$ & $0.72 \pm 0.61^{\mathrm{b}, \mathrm{c}}$ \\
$\mathbf{1 2}$ & $0.39 \pm 0.54^{\mathrm{c}, \mathrm{d}}$ \\
$\mathbf{1 5}$ & $0.23 \pm 0.43^{\mathrm{c}, \mathrm{d}}$ \\
\hline
\end{tabular}


Table 3 Life table parameters of M. macrocopa. All values are mean \pm standard deviation $(n=3)$. The different small letters indicate significant different between different salinity $(P<0.05)$.

\begin{tabular}{|c|c|c|c|c|c|c|}
\hline $\begin{array}{l}\text { Salinity } \\
\text { (ppt) }\end{array}$ & $\begin{array}{l}\text { Average initial } \\
\text { age of } \\
\text { reproduction } \\
\text { (days) }\end{array}$ & $\begin{array}{c}\text { Average longevity } \\
\text { (days) }\end{array}$ & $\begin{array}{c}\text { Net } \\
\text { Reproduction rate }\end{array}$ & $\begin{array}{c}\text { Gross reproduction } \\
\text { rate }\end{array}$ & Generation time & $\begin{array}{c}\text { Intrinsic rate of } \\
\text { population } \\
\text { increases }\end{array}$ \\
\hline 0 & $4.33 \pm 0.58^{a}$ & $12.33 \pm 0.58^{a}$ & $12.35 \pm 0.77^{a}$ & $13.33 \pm 0.58^{a}$ & $7.48 \pm 0.46^{a}$ & $0.16 \pm 0.007^{a}$ \\
\hline 4 & $5.33 \pm 0.58^{b}$ & $9.67 \pm 0.58^{a, b}$ & $9.45 \pm 0.77^{b}$ & $12.00 \pm 1.00^{b}$ & $7.70 \pm 0.19^{b}$ & $0.057 \pm 0.028^{a, b}$ \\
\hline 6 & $6.00 \pm 0.58^{a, b}$ & $9.67 \pm 0.58^{a, c}$ & $4.92 \pm 1.91^{a, b}$ & $11.00 \pm 7 \times 10^{5 a}$ & $6.98 \pm 0.96^{c}$ & $0.061 \pm 0.004^{a, c}$ \\
\hline 8 & $12.54 \pm 0.58^{a}$ & $3.35 \pm 0.62^{a, d}$ & $2.34 \pm 0.77^{a, d}$ & $5.34 \pm 0.58^{a}$ & $11.23 \pm 0.77^{d}$ & $0.078 \pm 0.004^{a, d}$ \\
\hline 12 & - & - & - & - & - & - \\
\hline 15 & - & - & - & - & - & - \\
\hline
\end{tabular}

*Life table parameters for 12psu and 15psu cannot be measured and recorded because all the treatments dead before being able to reproduce. 
Table 4 Fatty acid composition (\% total fatty acids) of Moina macrocopa grown at different salinities. All values are mean \pm standard deviation ( $\mathrm{n}=3$ ). The different small letters indicate significant different between; different salinity $(\mathrm{P}<0.05)$. The bold fatty acid species are described in the results.

\begin{tabular}{|c|c|c|c|c|c|c|}
\hline Fatty acid species & 0psu & 4 psu & $6 \mathrm{psu}$ & $8 p s u$ & 12psu & 15psu \\
\hline \multicolumn{7}{|l|}{ Saturated } \\
\hline $\mathrm{C} 14: 0$ & $4.68 \pm 0.01$ & $4.34 \pm 0.06$ & $2.68 \pm 0$ Salinities & $0.61 \pm 0.03$ & $0.24 \pm 0.03$ & $0.11 \pm<0.01$ \\
\hline C16:0 & $14.97 \pm 0.24^{\mathrm{a}}$ & $10.22 \pm 0.69^{b}$ & $11.09 \pm 0.83^{c}$ & $7.78 \pm 0.57^{d}$ & $5.58 \pm 0.05^{\mathrm{e}}$ & $0.90 \pm 0.30^{f}$ \\
\hline Sum & 19.65 & 14.56 & 13.77 & 8.39 & 5.82 & 1.01 \\
\hline \multicolumn{7}{|l|}{ Monosaturated } \\
\hline C16:1 & $7.41 \pm 1.45$ & $6.78 \pm 0.15$ & $5.58 \pm 0.05$ & $4.68 \pm 0.01$ & $3.37 \pm 0.03$ & $1.19 \pm 0.04$ \\
\hline $\mathrm{C} 18: 1^{\mathrm{c}}$ & $17.96 \pm 0.39^{\mathrm{a}}$ & $16.45 \pm 3.7^{b}$ & $14.62 \pm 2.5^{c}$ & $11.78 \pm 0.04^{\mathrm{d}}$ & $9.6 \pm 1.11^{\mathrm{e}}$ & $6.54 \pm 0.81^{\mathrm{f}}$ \\
\hline $\mathrm{C} 22: 1^{\mathrm{c}}$ & $0.79 \pm 0.08$ & $0.77 \pm 0.16$ & $0.66 \pm 0.01$ & $0.38 \pm 0.02$ & $0.19 \pm 0.04$ & $0.09 \pm 0.07$ \\
\hline Sum & 26.16 & 24 & 20.86 & 16.84 & 13.16 & 7.82 \\
\hline \multicolumn{7}{|l|}{ Polyunsaturated } \\
\hline C18:2b & $31.66 \pm 0.64^{a}$ & $23.69 \pm 1.6^{b}$ & $12.23 \pm 0.18^{c}$ & $10.22 \pm 0.69^{\mathrm{d}}$ & $7.78 \pm 0.57^{\mathrm{e}}$ & $3.23 \pm 0.52^{f}$ \\
\hline C18:3a(ALA) & $16.45 \pm 3.7^{\mathrm{a}}$ & $13.08 \pm 0.04^{b}$ & $12.38 \pm 0.02^{c}$ & $11.78 \pm 0.04^{\mathrm{d}}$ & $6.54 \pm 0.81^{\mathrm{e}}$ & $0.59 \pm<0.01^{\mathrm{f}}$ \\
\hline C18: $4^{a}$ & $14.64 \pm 2.5^{\mathrm{a}}$ & $13.09 \pm 0.04^{b}$ & $11.78 \pm 0.04^{c}$ & $10.91 \pm 0.03^{\mathrm{d}}$ & $9.00 \pm 1.41^{\mathrm{e}}$ & $4.58 \pm<0.01^{\mathrm{f}}$ \\
\hline C20:4b(ARA) & $0.57 \pm 0.19$ & $0.38 \pm 0.02$ & $0.0 .14 \pm 0.06$ & $0.12 \pm 0.01$ & $0.06 \pm<0.01$ & $0.04 \pm<0.01$ \\
\hline C20:5a(EPA) & $35.21 \pm 0.67^{a}$ & $31.68 \pm 0.64^{b}$ & $20.15 \pm 1.6^{c}$ & $19.99 \pm 1.2^{\mathrm{d}}$ & $14.96 \pm 1.10^{\mathrm{e}}$ & $4.68 \pm 0.01^{f}$ \\
\hline C22:6a(DHA) & $0.42 \pm 0.06$ & $0.35 \pm 0.19$ & $0.19 \pm 0.04$ & $0.09 \pm<0.01$ & $0.07 \pm<0.01$ & $0.04 \pm<0.01$ \\
\hline Sum & 98.95 & 82.27 & 56.87 & 53.11 & 38.41 & 13.16 \\
\hline
\end{tabular}

${ }^{\mathrm{a}} \omega-3$ fatty acids, ${ }^{\mathrm{b}} \omega-6$ fatty acids, and ${ }^{\mathrm{c}} \omega-9$ fatty acids.

*ALA: Alpha-linolenic acid; ARA: Arachidonic acid; EPA: Eicosapentaenoic acid; DHA: Docosahexaenoic acid. 


\section{Discussion}

Freshwater ecosystems are now becoming increasingly threatened, partly due to the rise in salinity of groundwater (i.e., from seawater intrusion) and, water regime modifications which reduce the frequency of high-flow, flushing events (Iannacone \& Alvarino, 2002; Ca nedo-Arguelles et la., 2016; Kayla et al., 2017) and, these will significantly impact both the survival rate (Rahma et al., 2017) and, reproduction (Grezesiuk and Mikulski, 2006; Bezirci et al., 2012; Rahma et al., 2017) of M. macrocopa. This study demonstrated how the increase of salinity especially the content of sodium chloride $(\mathrm{NaCl})$ affects survival and life history traits of a freshwater cladoceran species through an examination of effects on M. macrocopa which would be representative of impact to an ecological area. The results of the present study indicated that the increase in salinity influenced survival, growth and, reproduction of M. macrocopa.

M. macrocopa achieved the highest recorded survival rate at treatment salinity of 0psu, compared to other salinity range treatments. As indicated by Haridevan et al., (2015) for another species of cladoceran, Latonopsis australi, L. australis had the highest survival rate recorded for environmental salinity of $0 \mathrm{psu}$ which also decreased with the increase of the salinity level in the natural environment. Moreover, according to the study of Cabrera et al., (2014), the survival rate of Moina eugenie decreased with increase in salinity and, Ghazy et al., (2009) further supported this where survival rate of Daphnia magna was shown to decrease with increasing salt concentration. It is concluded that the survival rate of M. macrocopa is undoubtedly, significantly affected by the increase of salinity levels.

The current study showed that growth of M. macrocopa does not experience a significant reduction in environments with high salinities, up to a point. Results showed positive growth of $M$. macrocopa in salinity levels from 0psu until 6psu. However, when salinity was increased to 8, 12 and $15 \mathrm{psu}$, the growth of M. macrocopa became slower. Slowest growth was observed to occur at 15psu, which might have been a result of some regulatory stress that occur in the culture (Zhao et al., 2006). This conclusion is also aligned with the findings of Inger et al., (2010) investigating the growth rate of exotic cladoceran, Daphnia exilis which also did not show any changes under salinity regime of 6psu but, started to decline in growth when salinity reached 8psu and above.

Female reproduction was affected by salinity and, the maturation of M. macrocopa was delayed at the highest salinity. These results are comparable to those obtained by Albert et al., (2011), who noted that sexual maturation of M. macrocopa was delayed by 1 day at a salinity level of $5.5 p s u$ when compared to 0psu. Additionally, Ghazy et al., (2009), noted that the reproduction age of D. magna was delayed from 7 days until 9 days at salinity levels of 0 psu and 2.66psu, respectively.

The results from the current study showed that the average lifespan of M. macrocopa was 12.3 days of 0 psu and, 9.6 days at 6psu. These are similar results to study by Fernando and Laura (2007), where average lifespan of D. magna was also significantly affected by salt concentration and where results showed that maximum average lifespan (57.7 days) occurred at the salinity of $0 \mathrm{psu}$, whereas shortest lifespan (25.2 days) occurred at 7psu. Furthermore, in studies of Simocephalus vetulus, results also showed that the lifespan of this cladoceran decreased drastically when the salinity level was increased (Didem and Duygu, 2014).

Offspring net and gross reproduction rates of M. macrocopa were also affected when salinity increased. The previous study also showed that the number of offspring produce was the most affected parameters on the life table as caused by an increase of salinity for D. magna and D. longispina 
(Goncalves et al., 2007). Furthermore, in an observation-based study by Haridevan et al., (2015), the findings also showed that the offspring of Latonopsis australis were significantly influenced by high salinity. It is concluded that salinity clearly impacts reproduction of offspring of this cladoceran.

Salinity levels impact the intrinsic rate (births minus deaths) for M. macrocopa population. This claim was supported in similar research done by Haridevan et al. (2015) where the intrinsic rate of Latonopsis australis decreased when the salinity levels of treatments increased. In the current study, life table parameters at salinity more than 8 psu also cannot be reliable acquired because salinity higher than 8psu is beyond the toleration of M. macrocopa. El Gamal et al., (2014) also noted that D. longispina reproduced and lived well in salinity below 5 psu but then, started to decline when salinity levels increased. Thus, the present study concludes that M. macrocopa can achieve the optimum growth population when salinity is below $6 \mathrm{psu}$. Zooplankton is sensitive to change in the aquatic environment that can cause a significant change in ambient conditions within the aquatic ecosystem (Harish and Kiran, 2016). The increase of salt concentration can cause the disappearance of species that cannot tolerate highly saline conditions and, salinity is known to be a strong mechanism that can change aquatic communities (Maria et al., 2012).

Furthermore, no life table data can be recorded for 12psu and 15psu since the M. macrocopa are dead before being able to reproduce. Therefore, various freshwater invertebrate species (including cladocerans) are more sensitive to $\mathrm{NaCl}$ salinity than to the effect produced by the array of chemical compounds present in sea salt (Kefford et al., 2004). Higher content of salinity level might be fatal to freshwater cladocerans especially M. macrocopa. The highest data can be recorded for life table parameter only at 8psu. It is strongly supported by Ghazy et al., 2009, that the highest salinity can provoke stressful condition for cladocerans and cause mortality. Apart from that, M. macrocopa that spending most of their life stages under good conditions (food and environment) may adapt their life only with considerable time-lags are more vulnerable to starvation when there is decreasing food concentrations, and stressful environment occur and indirectly cause mortality among this species.

Observations in the current study showed that the expression of fatty acid is higher at the optimum culture conditions ( $0 \mathrm{psu}$ and $4 \mathrm{psu}$ ) compared to other salinity level treatments. This effect is probably due to the minimal stress undergone by the cultured M. macrocopa at these optimum conditions which is finally reflected in the obtainment of a rich fatty acid profile. Similar observations were also reported (Zaleha and Busra, 2012; Zaleha et al., 2014) where live feed underwent minimal stress during the culture period produced superior survival, growth and reproduction. High polyunsaturated fatty acids achieved by M. macrocopa might be due to the use of Nannochloropsis sp. as food sources, which was conducted to imitate feed in the natural environment. The amount of EPA and DHA in algae varies greatly among different algal species and environmental conditions. EPA content in Nannochloropsis sp. is $23.4 \mathrm{mg} \mathrm{g}^{-1}$ (Rasdi and Qin, 2018). Microalgae such as Nannochloropsis sp. have received increasing interest as a target live feed for aquatic animals because of the high contents of EPA (Patil et al., 2007).

\section{Conclusions}

In conclusion, survival, growth, reproduction rate and fatty acid profile of M. macrocopa were affected by different treatment ranges of salinity. M. macrocopa produced better growth rate, survival rate and, productivity at the salinity of $0 \mathrm{psu}$ which is a normal freshwater environment. Salinity at 4 psu also provided relatively better growth for M. macrocopa and, most of the results from the present 
study showed that there is no significant difference between salinity treatments of $0 \mathrm{psu}$ and $4 \mathrm{psu}$. Salinity above $8 \mathrm{psu}$, was found to be intolerable for M. macrocopa and to be above the critical salinity maximum (CSMax) or acute phase for cladoceran. Apart from that, fatty acid content also significantly abated with increased salinity levels. The highest content of fatty acid produced was with M. macrocopa being cultured in optimal salinity levels of $0 \mathrm{psu}$ and $4 \mathrm{psu}$, which are considered to be normal in their natural habitat.

Comparing results in the whole $\mathrm{NaCl}$ concentration range tested, we can conclude that the impairment effects on fatty acid content, growth, reproduction and survival under the current treatments were provoked by salinity stress. Although the result of the present study shows that the survival rate, life history and fatty acids of $M$. macrocopa were significantly affected by the increase in salinity, future detailed studies are required to understand how freshwater species, including other species of zooplankton, can adapt to a higher saline stressed environment. Thus, these findings can be used by future researchers for further study and research on the development of species characterization and, on the factors affecting the abundance and zooplankton composition within the freshwater community, thus providing more ecologically relevant information on primary productivity in the ecosystem.

Funding : This work is fully supported by the Knowledge Transfer Grant under Ministry of Higher Education Malaysia (Vot Number 58106).

Author Contributions: N.W.R, H.S.A,Y,S.N had designed the research. M.I and M.A.G assist in monitoring the students. A.H involved in providing ideas through his previous works. All authors participated in the writing, review and editing of the manuscript.

Acknowledgments: We wish to thank our laboratory and hatchery assistances En. Mat Zain, En. Yaacob and En. Adhwa for their advice and facilities support. This paper was supported by Ministry of Higher Education through Knowledge Transfer Programme.

Conflicts of Interest: The authors declare no conflict of interest.

\section{References}

1. Albert L. Suhett, Christian E. W. Steinberg, Jayme M. Santangelo, Reinaldo L. Bozelli, Vinicius F. Farjalla, 2011. Natural dissolved humic subtances increases the lifespan and promote transgenerational resistance to salt stress in the cladoceran Moina macrocopa. Environ Sci Pollut Res 18, 1004-1014. doi:10.1007/s11356-011-0455-y.

2. Ana Carolina Brito Vieira, Ana Maria Alves Medeiros, Leonardo Leoncio Ribeiro, Maria Cristina Crispim, 2011. Population Dynamics of Moina minuta (Hansen, 1899), Ceriodaphnia cornuta (Sars, 1886), and Diaphanosoma spinulosum (Herbst, 1967) (Crustacean: Branchiopoda) in Different Nutrients ( $\mathrm{N}$ and $\mathrm{P}$ ) Concentration Ranges. Acta Limnologica Brasiliensia 23(1), 1-9. doi:10.4322/actalb.2011.018.

3. Bezirci, G., S. B. Akkas, K. Rinke, F. Yildirim, Z. Kalaylioglu, F. Severcan and M. Beklioglu, 2012. Impacts of salinity and fish-exuded kairomone on the survival and macromolecular profile of Daphnia pulex. Ecotoxicology 21, 601-614. doi:10.1007/s10646-011-0820-0.

4. Bruno B. Castro, Claudia Loureiro, Ana P. Cuo, M. Armida Pedrosa, Fernando Goncales, 2012. Life-history responses of salinity-tolerant and salinity-sensitive lineages of stenohaline 
cladocerans do not confirm clonal differentiation. Hydrobiologia 702, 73-82. doi:10.1007/s10750012-1308-5.

5. Cabrera Gabriela, Vignatti Alicia, Echaniza Santiago, 2014. Acute effects of Nacl and Na2SO4 on Daphnia menucoensis Paggi, 1996 and Moina eugeniae Olivier, 1954 (Crustacea, Cladocera). Research Zoology 4(1), 8-12. doi:10.5923/j.zoology.20140401.02.

6. Ca nedo-Argüelles, M., Hawkins, C.P., Kefford, B.J., Schaefer, R.B., Dyack, B.J., Brucet, S., Buchwalter, D., Dunlop, et al., 2016. Saving freshwater from salts. Science 351, 914-916. doi:10.1126/science.aad3488.

7. Didem Gokce and Duygu Ozhan Turhan, 2014. Effects of salinity tolerance on survival and life history of 2 cladocerans. Turkish Journal of Zoology 38, 347-353. doi:10.3906/zoo-1304-21.

8. Ekaterina Yu. Afonina, Natalya A. Tashlykova, 2017. Plankton community and the relationship with the environment in slaine lakes of Onon-Torey plain, Northeastern Mongolia. Saudi Journal of Biological Sciences. doi:10.1016/j.sjbs.2017.01.003.

9. El- Gamal MM, Mona MH, Abdel RF, Salim HK, Nour Eldeen MF, 2014. Salinity and temperature effect on survival and life history of freshwater cladoceran Daphnia longispina inhabiting Egyptian water. Sci-Afric Journal of Scientific Issues, Research and Essays 2(8), 365-374.

10. Emanuela Cristina Freitas, Odete Rocha, 2010. Acute and chronic effects of sodium and potassium on the tropical freshwater cladoceran Pseudosida ramosa. Ecotoxicology 20, 88-96. doi:10.1007/s10646-010-0559-z.

11. Erondu, C. J., and Solomon, R. J., 2017. Identification of planktons (zooplankton and phytoplankton) behind girls' hostel University of Abuja, Nigeria. Direct research journal of public health and environmental technology 2(3), 21-29. doi:10.26765/DRJPHET.2017.2763.

12. Fernando Martinez-Jeronimo and Laura Martinez-Jeronimo, 2007. Chronic effect of $\mathrm{NaCl}$ salinity on a freshwater strain of Daphnia magna Straus (Crustacea: Cladocera): A demographic study. Ecotoxicology and environment safety 67, 411-416. doi:10.1016/j.ecoenv.2006.08.009.

13. Forro 1, Korovchinsky NM, Kotov AA, Petrusek A, 2008. Global diversty of cladoceran (Cladocera; crustacean) in freshwater animal diversity assessment. Hydrobiologia 595, 177 - 184.

14. Gama-Flores JL, Huidobro-Salas ME, Sarma SSS, Nandini S, Zepeda-Mejia R \& Gulati RD 2015. Temperature and age affect the life history characteristics and fatty acid profiles of Moina macrocopa (Cladocera). Journal of Thermal Biology 53: 135-142. doi:10.1016/j.jtherbio.2015.10.005.

15. Gani, Paran, Mohamed sunar, Norshuhaila, Peralta, Hazel Monica, Abdul Latiff, Ab Aziz, A b. Razak, and Abdul Rafiq, 2016. Influence of Initial Cell Concentrations on the Growth Rate and Biomass Productivity of Microalgae in Domestic Wastewater. Applied Ecology and Environmental Research 14. 399-409. doi:10.15666/aeer/1402_399409.

16. Ghazy Mahassen M. El-Deeb, Madlen M. Habashy, Faika I. Kossa, and Eman Y. Mohammady 2009. Effects of salinity on survival, growth and reproduction of the water flea, Daphnia magna. Nature and Science 7 (11), 28-42.

17. Goncalves, A. M. M., Castro, B. B., Pardal, M. A., Goncalves, F., 2007. Salinity effects on survival and life history of two freshwater cladocerans (Daphnia magna and Daphnia longispina). Ann. Limnol. - Int. J. Lim. 43(1), 13-20. doi:10.1051/limn/2007022.

18. Hasnun N. Ismail, Jian G. Qin, Laurent Seuront 2011. Dietary responses of the brackish cladoceran Daphniopsis australis fed on different algal species. Journal of Experimental Marine Biology and Ecology 409, 275- 282. doi:10.1016/j.jembe.2011.09.008. 
19. Grzesiuk, M. and A. Mikulski, 2006. The effect of salinity on freshwater crustaceans. Polish Journal of Ecology 54, 669-674.

20. Haridevan, G., Jyothibabu, R., Arunpandi, N., Jagadesan, L., Biju, L., 2015. Influence of salinity on the life table demography of a rare cladoceran Latonopsis australis. Environ Monit Assess 187, 643. doi:10.1007/s10661-015-4849-z.

21. Harish Kumar and Kiran, 2016. A report on diversity of cladocera in sewage fed tank of Bhadravathi taluk, Karnataka. International Journal of fauna and Biologocal Studies 3(2), 18-20.

22. Hardy Elsa. R. and Duncan A., 1994. Food Concentration and Temperature Effects on Life Cycle Characteristics of Tropical Cladocera (Daphnia gessneri Herbst, Diaphanosoma sarsi Richard, Moina reticulate (Daday)): I. Development Time. ACTA AMAZONICA 24(1/2), 119-134. doi:10.1590/180943921994242134.

23. Ichihara, K. \& Fukubayashi, Y., 2010. Preparation of fatty acid methyl esters for gas-liquid chromatography. Journal of Lipid Research. 51(3), 635-40. doi:10.1194/j1r.D001065.

24. Inger Heine Fuster, Caren Vega Retter, Pablo Sabat, Rodrigo Ramos Jiliberto, 2010. Osmoregulatory and demographic responses to salinity of the exotic cladoceran Daphnia exilis. Journal of Plankton Research 32(10), 1405-1411. doi:10.1093/plankt/fbq055.

25. Iannacone, O., \& Alvariño, F., 2002. Evaluation of the environmental risk of cartep insecticide in bioassays with three invertebrates. Technical Agriculture, 62(3), 366-374. doi:10.4067/S036528072002000300003.

26. Loh. Jiun Yan, Han Kiat Alan Ong, Yii Siang Hii, Thomas J. Smith, Malcolm M. Lock, Gideon Khoo, 2012. Impact of Potential Food Sources on the Life Table of The Cladoceran, Moina macrocopa. The Israeli Journal of Aquaculture - Bamidgeh, IJA 65, 8 pages.

27. Kayla D. Coldsnow, Brian M. Matters, William D. Hintz, Rick A. Relyea, 2017. Rapid evolution of tolerance to road salt in zooplankton. Environmental pollution 222, 367-373. doi:10.1016/j.envpol.2016.12.024.

28. Kefford, B.J., Palmer, C.G., Pakhomova, L., and Nugegoda, D. 2004. Comparing test systems to measure the salinity tolerance of freshwater invertebrates. Water SA 30, 499-506.

29. Maria Anton-Pardo and Zavier Armengol, 2012. Effects of salinity and water temporality on zooplankton community in coastal Mediterranean ponds. Estuarine, Coastal and Shelf Science 114, 93-99.

30. M. N. Lani, N. F. Malek Rivan, A. Ismail, W. B. Wan Omar, Z. Hassan, and Z. Suhaili, 2018. Comparative Study of Physico-Chemical Analyses of Different Water Resources in Setiu Wetland, Terengganu. Food Science and Technology 25-37. doi:10.1007/978-3-319-92264-5_3.

31. Patil V., Källqvist T., Olsen E., Vogt G., Gislerød H., 2007. Fatty acid composition of 12 microalgae for possible use in aquaculture feed. Aquaculture International, 15, 1-9. doi:10.1007/s10499-0069060-3.

32. Püttmann, M., Krug, H., von Ochsenstein, E. \& Kattermann, R., 1993. Fast HPLC Determination of Serum Free Fatty Acids in the Picomole Range. Clinical chemistry 39, 825-32.

33. Rahma Tabet, Habib Ayadi, Marcel Koken, Vincent Leignel, 2017. Homeostatic responses of crustaceans to salinity changes. Hydrobiologia 799, 1-20. doi:10.1007/s10750-017-3232-1.

34. Rasdi N.W., Qin J.G., 2018. Impact of food type on growth, survival and reproduction of the cyclopoid copepod Cyclopina kasignete as a potential live food in aquaculture. Aquaculture International, 26, 1281-1295. doi:10.1007/s10499-018-0283-x. 
35. Reliana Lumban Toruan, 2012. Zooplankton community emerging from fresh and saline wetlands. Ecohydrology Hydrobiology 12(1), 53-63. doi:10.2478/v10104-012-0003-5.

36. Rihab Bouchnak, Christian E.W. Steinberg, 2013. Algal diets and natural xenobiotics impact energy allocation in cladocerans. II. Moina macrocopa and Moina micrura. Limnologica 44, 23-31. doi:10.1016/j.limno.2013.06.002.

37. Rottmann, R. W., Scott Graves, J., Craig Watson, Roy P.E. Yanong, 2014. Culture Techniques of Moina: The Ideal Daphnia for Feeding Freshwater Fish Fry. UF/IFAS Tropical Aquaculture Laboratory 813, 671-5230.

38. Sarma, S. S. S., \& Nandini, S., 2006. Review of recent ecotoxicological studies on cladocerans. Journal of Environmental Science and Health, Part B, 41(8), 1417-1430. doi:10.1080/03601230600964316.

39. Scharf, F.S., J. P. Manderson and M.C. Fabriziob, 2006. The effects of seafloor habitat complexity on survival of juvenile fishes: Species-specific interactions with structural refuge. Journal of Experimental Marine Biology and Ecology 335, 167-176. doi:10.1016/j.jembe.2006.03.018.

40. Soni, H. B. and S. Thomas, 2014. Occurrence of zooplanktons at sacred palustrine habitat, Central Gujarat, India, with conservation and management strategies. International Journal of Environment 3(1), 111-121.

41. Souza, A.T., E. Dias, A. Nogueira, J. Campos, J.C. Marques and I. Martin, 2013. Population ecology and habitat preferences of juvenile flounder Platichthys flesus (Actinopterygii: Pleuronectidae) in a temperate estuary. Journal of Sea Research 79, 60-69. doi:10.1016/j.seares.2013.01.005.

42. Suratman S., Hussein A. N.A. R., Latif M. T., and Weston K., 2014. Reassessment of PhysicoChemical Water Quality in Setiu Wetland, Malaysia. Sains Malaysiana 43(8) (2014), 1127-1131.

43. Zaleha Kassim, Muhammad Solleh Majid, Nur yahdiyani Mat Alwi and Hazwani Hanim Hasnan, 2018. Diet preferences of small fishes at Setiu Lagoon, Malaysia. Ecology and Sustainable Development 1(1), 9-17. doi:10.22606/esd.2018.11002.

44. Zaleha, K., Akbar John, B., Lim Keng, C., Nur Farahiyah, Z. \& Nur Hidayah, A., 2014. Sustainable Technique for Selected Live Feed Culture. In Sustainable Aquaculture Techniques. Martha Hernandez-Vergara (Edi.), ISBN: 978-953-51-1224-2, InTech, doi:10.5772/57212.

45. Kassim, Zaleha and John, Akbar and Asgnari, $\mathrm{H}$ and, Al-Aama \& Miskon, Fuad., 2014. Fatty acid profiling of benthic harpacticoid (Pararobertsonia sp.) exposed to environmental stresses. Malaysian Applied Biology. 43. 31-39.

46. Zaleha Kassim and Busra Ibrahim 2012. Culture of Harpacticoid Copepods: Understanding the Reproduction and Effect of Environmental Factors, Aquaculture, Dr. Zainal Muchlisin (Ed.), ISBN: 978-953-307-974-5, InTech. doi:10.5772/28373.

47. Zhao W1, Yu B, Wang T, Song L., 2006. Adaptability of Moina affinis (Crustacea: Cladocera: Moinidae) to seawater salinity. Journal of Applied Ecology 17(8), 1521-152. 